\title{
The Effect of Distal Fusion Level on Functional and Radiographic Parameters in Degenerative Spine Following Long Posterior Instrumentation and Fusion
}

\author{
Semih Kivanc OLGUNER ${ }^{1}$, Mustafa CELIKTAS ${ }^{2}$, Ali ARSLAN ${ }^{1}$, Ismail ISTEMEN ${ }^{1}$, Yurdal GEZERCAN ${ }^{1}$, \\ Ali Ihsan OKTEN ${ }^{1}$, Mahir GULSEN²
}

${ }^{1}$ Adana City Training Research Hospital, Department of Neurosurgery, Adana, Turkey

${ }^{2}$ Ortopedia Hospital, Department of Spine Surgery, Adana, Turkey

Corresponding author: Semih Kivanc OLGUNER kivanc3olguner@hotmail.com

\section{ABSTRACT}

AIM: To investigate the effect of distal fusion level on radiographic parameters and functional outcome in patients with degenerative spine disease who undergo long posterior fusion with instrumentation.

MATERIAL and METHODS: This study included 78 adult patients aged $>60$ years who underwent long posterior fusion (>6 levels) for spinal deformity with a minimum 2-year follow-up. The patients were divided into two groups based on distal fusion level (L5 group and iliac group). Spinopelvic parameters, including lumbar lordosis (LL) and sagittal vertical axis (SVA), were evaluated. Functional outcome was evaluated with the pain visual analog scale (VAS) and the Oswestry Disability Index (ODI) questionnaire. Correlations between clinical and radiographic parameters were calculated statistically.

RESULTS: In the L5 group, the mean SVA and LL significantly improved after surgery ( $p=0.025$ and 0.008 , respectively). Similarly, the SVA and LL also improved significantly in the iliac group ( $p=0.002$ and 0.001 , respectively). In both groups, lumbar VAS, leg VAS and ODI scores significantly improved $(p<0.001)$. The change in ODI score was significantly greater in the iliac group than the $L 5$ group $(\mathrm{p}=0.013)$.

CONCLUSION: Although patients did not achieve the desired optimal spinal saggital balance, both L5 and iliac groups showed significant improvement in VAS and ODI scores. The iliac group showed slightly better improvement in ODI score.

KEYWORDS: Clinical outcome, Distal fusion level, Long posterior instrumentation

\section{INTRODUCTION}

L ong posterior fusions are frequently used in adult patients to correct spinal malalignment but there is still debate Jregarding inclusion of the L5-S1 motion segment in the construct $(3,25)$. Stopping at L5 preserves L5-S1 motion, but may result in subsequent disc degeneration leading to pain, spinal malalignment, and possible need for revision surgery. Conversely, stopping at $\mathbf{S} 1$ requires more extensive surgical dissection and may result in failure of the instrumentation, loss of lumbar lordosis, and pseudoarthrosis (18). The mechanism for pseudoarthrosis in this instance is a cantilever force from a heavy thoracolumbar load acting on the lumbosacral instrumentation in combination with poor sacral bone quality: the bone cannot withstand this pullout force. Therefore, the use of iliac screws has been recommended to maintain a more rigid lumbosacral fusion and provide improved correctionof sagittal balance. However, fusion extension to the ilium may increase the duration of surgery, the rate of implant-related complications, and operative blood loss $(1,12)$.
Semih Kivanc OLGUNER (1) : 0000-0002-5314-4636 Mustafa CELIKTAS

(D) : $0000-0003-2084-9725$ Ali ARSLAN
Ismail ISTEMEN

(1) : $0000-0002-2341-4818$

Yurdal GEZERCAN : : 0000-0002-4124-2036

Ali Ihsan OKTEN (10): 0000-0003-0292-201X
Mahir GULSEN (D) : 0000-0002-7268-5024 
Few studies have investigated the effect of long posterior fusion on patient outcomes and sagittal balance. Sagittal balance is the key factor that reflects clinical status in patients with spinal deformity and is primarily assessed with radiographic parameters. Maintaining optimal sagittal balance is associated with symptom relief, improved quality of life, and decreased disability $(10,26)$. Therefore, we aimed to investigate the effect of distal fusion level on radiographic parameters and functional outcome in patients who underwent long posterior fusion with instrumentation.

\section{MATERIAL and METHODS}

This study was conducted in accordance with the principles of the Declaration of Helsinki and was approved by the Ethics Committee of the Adana City Training and Research Hospital (19.06.2019 - 475). We retrospectively analyzed 78 patients with degenerative lumbar disease aged $>60$ years who underwent posterolateral fusion with pedicle screw fixation involving $>6$ segments that included either L5 or the ilium as the distal extent between January 2010 and February 2017. All patients had symptoms of back pain and radiculopathy and degenerative lumbar disease confirmed by plain radiographs and magnetic resonance imaging (MRI). All patients received a minimum of 2 years follow-up. Patients were excluded if they had a previous decompression or fusion involving L5 or S1.

The operations were performed by two senior spine surgeons. Pedicle screw fixation and laminectomy were performed through a posterior thoracolumbar incision. Interbody cage arthrodesis with graft was selectively performed in a small number of patients; those who received an L5-S1 interbody arthrodesis were excluded from the study.

L5-S1 disc degeneration was graded on pre- and postoperative $\mathrm{MRI}$ based on the Pfirmann classification (23). Intervertebral disc structure, height, and nucleus pulposus-annulus fibrosus distinction were evaluated on T2-weighted sequences and graded accordingly. Grades 0-3 were considered minor degeneration and grades 4 and 5 were considered major degeneration.

Full body standing anteroposterior and lateral radiographs were performed preoperatively, early postoperatively, at the first month follow-up examination and at every routine followup thereafter. Only the preoperative and final postoperative radiographs were included for analysis. The following parameters were measured and analyzed: sagittal vertical axis (SVA), T5-T12 thoracic kyphosis (TK), L1-S1 lumbar lordosis (LL), pelvic tilt (PT), sacral slope (SS), and pelvic incidence (PI).

Oswestry disability index (ODI) and Visual Analog Scale (VAS) assessments were performed preoperatively and once per year postoperatively. The ODI consists of 10 questions that evaluate functional disability related to back pain.

\section{Statistical Analysis}

All analyses were performed using SPSS software, version 20.0 (IBM, Inc., Armonk, NY, USA). Categorical variables are expressed as numbers and percentages; continuous variables are summarized as means with standard deviation. The patients were divided into two groups according to distal extent of the fusion: the iliac group (42 patients) and the L5 group (36 patients). The chi-square test was used to compare categorical variables between the groups. The normality of distribution for continuous variables was confirmed with the Shapiro-Wilk test. The Student's t-test was used to compare normally distributed continuous variables between the groups; the Mann-Whitney $U$ test was used in case of non-normal distribution. For comparison of preoperative and postoperative variables, the paired samples t-test was used. $p<0.05$ was considered significant.

\section{RESULTS}

Seventy-eight patients with lumbar degenerative deformity were evaluated (Table I). Mean overall follow-up was 41 months and did not differ significantly between the L5 and iliac groups ( 40 months vs. 42.5 months, $p=0.548$ ). The number of fused vertebral levels was significantly fewer in the L5 group than the iliac group (8 levels vs. 10 levels, $p=0.002$ ). In the iliac group, SVA significantly improved from $97 \mathrm{~mm}$ (range, $18-235)$ to $65 \mathrm{~mm}$ (range, $0-240)(\mathrm{p}=0.002)$; lumbar lordosis significantly improved from $27.69^{\circ} \pm 14.77^{\circ}$ to $39.95^{\circ} \pm 7.42^{\circ}$ $(p<0.001)$; thoracic kyphosis significantly increased from $28^{\circ}$ (range, $17-50)$ to $33^{\circ}$ (range, 20-65) $(\mathrm{p}<0.001)$; and pelvic tilt significantly decreased from $28.19^{\circ} \pm 5.32^{\circ}$ to $22.43^{\circ} \pm 4.52^{\circ}$ $(p<0.001)$. Additionally in the iliac group, the back pain VAS score significantly improved from 8 (range, 4-10) to 4 (range, $0-10)(p<0.001)$; leg pain VAS score significantly improved from 7.5 (range, $0-10$ ) to 2 (range, $0-10)$ ( $p<0.001$ ); and ODI score improved from $71.15 \pm 17.69$ to $43.25 \pm 21.77(p<0.001)$ (Table II).

In the L5 group, SVA significantly decreased from $81 \mathrm{~mm}$ (range, 15-230) to $60 \mathrm{~mm}$ (range, 14-170) $(\mathrm{p}=0.025)$; lumbar lordosis significantly improved from $33.50^{\circ} \pm 16.92^{\circ}$ to $40.50^{\circ}$ $\pm 11.68^{\circ}(p=0.008)$; pelvic tilt significantly decreased from $29.94^{\circ} \pm 7.46^{\circ}$ to $23.89^{\circ} \pm 4.55^{\circ}(p<0.001)$; and thoracic kyphosis significantly increased from $34^{\circ}$ (range, 11-49) to $39^{\circ}$ (range, 21-55) $(p<0.001)$. Similar to the iliac group, back pain VAS, leg pain VAS, and ODI scores also showed a significant improvement in the L5 group $(\mathrm{p}<0.001)$ (Table III).

Table IV shows the comparison of radiological and clinical changes between the groups.

Improvement of ODI was significantly greater in the iliac group than the L5 group $(p=0.013)$.

Surgical complication soccurred in $44.9 \%$ of all patients. These included implant failure, screw malpositioning, cerebrospinal fistula (CSF) fistula, fracture, infection, hematoma, proximal junctional kyphosis and failure, and distal adjacent segment disease. There was no significant difference in the complication rate between the groups $(p=0.367)$.

\section{DISCUSSION}

Facet arthropathy, disc degeneration, loss of disc height, and thickening of the ligamentum flavum and posterior 
longitudinal ligament may lead to sagittal and/or coronal malalignment of the spine. In a previous study of 752 patients, sagittal balance was reported to be the most important factor influencing patient outcome and symptom severity increased with progressive sagittal imbalance (11).
SVA (the distance between the center of the $\mathrm{C} 7$ vertebral body and the posterior superior end plate of the sacrum) increases in the linear plane with advancing age. In order to provide balance and create a stable posture against gravity, the patient compensates with retroversion of the pelvis and

Table I: Comparison of Demographic Variables Between the lliac and L5 Groups

\begin{tabular}{|c|c|c|c|c|}
\hline \multirow[b]{3}{*}{ Parameters } & \multicolumn{3}{|c|}{ Group } & \multirow[b]{2}{*}{$\mathbf{p}$} \\
\hline & Total & Iliac & L5 & \\
\hline & $\begin{array}{c}\text { Median (range) or } \\
\text { number (percentage) }\end{array}$ & $\begin{array}{c}\text { Median (range) or } \\
\text { number (percentage) }\end{array}$ & $\begin{array}{c}\text { Median (range) or } \\
\text { number (percentage) }\end{array}$ & \\
\hline Age, years & $69(60$ / 86) & $67.5(60 / 80)$ & $72(60$ / 86) & 0.165 \\
\hline \multicolumn{5}{|l|}{ Gender } \\
\hline Female & $64(82.1)$ & $40(95.2)$ & $24(66.7)$ & \multirow{2}{*}{0.001} \\
\hline Male & 14 (17.9) & $2(4.8)$ & $12(33.3)$ & \\
\hline Follow-up time, months & $41(24 / 77)$ & $42.5(24 / 59)$ & $40(24 / 77)$ & 0.548 \\
\hline
\end{tabular}

Table II: Clinical and Radiographic Results in the lliac Group

\begin{tabular}{lccc}
\hline Parameters & Preoperative value & Postoperative value & $\mathbf{p}$ \\
\hline Back pain VAS & $8(4 / 10)$ & $4(0 / 10)$ & $<0.001$ \\
\hline Leg pain VAS & $7.5(0 / 10)$ & $2(0 / 10)$ & $<0.001$ \\
\hline ODI & $71.15 \pm 17.69$ & $43.25 \pm 21.77$ & $<0.001$ \\
\hline SVA $(\mathrm{mm})$ & $97(18 / 235)$ & $65(0 / 240)$ & $\mathbf{0 . 0 0 2}$ \\
\hline Pelvic Tilt $\left(^{\circ}\right)$ & $28.19 \pm 5.32$ & $22.43 \pm 4.52$ & $<0.001$ \\
\hline Sacral Slope $\left(^{\circ}\right)$ & $27.62 \pm 8.53$ & $33.40 \pm 9.76$ & $<0.001$ \\
\hline Pelvic incidence $\left(^{\circ}\right)$ & $54.5(35 / 75)$ & $54.5(35 / 75)$ & 0.999 \\
\hline Lumbar lordosis $\left(^{\circ}\right)$ & $27.69 \pm 14.77$ & $39.95 \pm 7.42$ & $<0.001$ \\
\hline Thoracic kyphosis $\left(^{\circ}\right)$ & $28(17 / 50)$ & $33(20 / 65)$ & $<0.001$ \\
\hline
\end{tabular}

Data is presented as mean scores and range or mean values and standard deviation.

Table III: Clinical and Radiographic Results in the L5 Group

\begin{tabular}{lccc}
\hline Parameters & Preoperative value & Postoperative value & $\mathbf{p}$ \\
\hline Back pain VAS & $8(5 / 10)$ & $5(1 / 8)$ & $<0.001$ \\
\hline Leg pain VAS & $7.5(0 / 10)$ & $3.5(0 / 9)$ & $<0.001$ \\
\hline ODI & $63.67 \pm 18.30$ & $47.17 \pm 24.76$ & $<0.001$ \\
\hline SVA $(\mathrm{mm})$ & $81(15 / 230)$ & $60(14 / 170)$ & $=0.025$ \\
\hline Pelvic Tilt $\left(^{\circ}\right)$ & $29.94 \pm 7.46$ & $23.89 \pm 4.55$ & $<0.001$ \\
\hline Sacral Slope $\left(^{\circ}\right)$ & $28.28 \pm 7.13$ & $34.00 \pm 7.78$ & $<0.001$ \\
\hline Pelvic incidence $\left(^{\circ}\right)$ & $58.5(44 / 78)$ & $58.5(44 / 78)$ & $=0.999$ \\
\hline Lumbar lordosis $\left(^{\circ}\right)$ & $33.50 \pm 16.92$ & $40.50 \pm 11.68$ & $=0.008$ \\
\hline Thoracic kyphosis $\left(^{\circ}\right)$ & $34(11 / 49)$ & $39(21 / 55)$ & $<0.001$ \\
\hline
\end{tabular}

Data is presented as mean scores and range or mean values and standard deviation. 
Table IV: Comparison of Radiological and Clinical Changes Between the Iliac and L5 Groups

\begin{tabular}{|c|c|c|c|c|}
\hline \multirow[b]{2}{*}{ Parameters } & \multicolumn{3}{|c|}{ Group } & \multirow{2}{*}{$\mathbf{p}$} \\
\hline & Median (range) & Median (range) & Median (range) & \\
\hline Back pain VAS & $4(3 / 9)$ & $5(2 / 9)$ & $3.5(3 / 8)$ & 0.093 \\
\hline Leg pain VAS & $4(4 / 10)$ & $4(0$ / 10) & $4(4 / 7)$ & 0.137 \\
\hline \multirow[t]{2}{*}{ SVA (mm) } & 22 (98 / 200) & 25.5 (95 / 200) & 20.5 (98 / 199) & 0.239 \\
\hline & $\begin{array}{c}\text { Mean } \pm \text { standard } \\
\text { deviation }\end{array}$ & $\begin{array}{c}\text { Mean } \pm \text { standard } \\
\text { deviation }\end{array}$ & $\begin{array}{c}\text { Mean } \pm \text { standard } \\
\text { deviation }\end{array}$ & \\
\hline Pelvic Tilt $\left({ }^{\circ}\right)$ & $5.90 \pm 5.18$ & $5.76 \pm 4.80$ & $6.06 \pm 5.66$ & 0.801 \\
\hline
\end{tabular}

the flexion of knees. As the anterior postural incline increases, the tension of the extensor muscles also increases $(7,14)$. These compensations are more common in patients aged $>60$ years andthe parameters that define sagittal balance may vary with age $(13,21)$. SVA has been reported to increase with age in several recent studies $(7,13,15)$. In addition, Lafage et al. found that ideal spinopelvic values increased with age and an SVAof $78.1 \mathrm{~mm}$ was the age-matched value for a 75 -year-old patient (21).

The effect of sagittal balance on ODI has been investigated in numerous studies. Some have noted that the radiographic parameters that determine sagittal balance appear to have a direct effect on ODI score and quality of life $(19,28)$. However, other studies have presented contrary findings. In a study of 220 asymptomatic patients, Yokoyama et al. examined the relationship between age and sagittal equilibrium, and found that lumbar lordosis was inadequate in an elderly population with SVA >50 mm; despite this, the patients were completely asymptomatic (30). In another study by Zaborovskii et al., sagittal balance parameters of patients were examined in pelvic and lumbar groups. Although the parameters of the lumbar group were not within optimal limits, their health-related quality of life and disability scores were good (31). Simon et al. found that less lordosis was associated with better quality of life because these patients also had a lower pelvic incidence and therefore better sagittal balance (27). In a Korean study, patients with SVA $>5 \mathrm{~cm}$ showed a significant improvement in clinical outcome (17). Ploumis et al. demonstrated that there was no significant difference between patients with sagittal plane plumbline offset $\geq 50 \mathrm{~mm}$ and those with offset $<50 \mathrm{~mm}$ with respect to Oswestry and Roland-Morris scores (24). In addition, yet another study found no association between clinical and radiographical parameters in patients with degenerative de novo lumbar scoliosis (9).
In this study, our results were similar to those above. The L5 and iliac groups did not achieve the desired optimal radiographic improvement postoperatively, but SVA, LL, and PT improved significantly (Figure 1A, B). In both groups, we found a significant improvement in ODI and VAS scores. One of the reasons may be that the postoperative SVA values in both groups were close to the age-compatible values determined in the Lafage et al.'s study (21). In addition, the decrease in PT values of both groups demonstrate improved pelvic compensatory mechanisms. This leads to decreased energy expenditure and muscle fatigue of the patients.

Compared tothe L5 group, the iliac group achieved better results in terms of ODI score improvement (Figure 2A, B). The main function of iliac screws is to preserve the lumbosacral junction by preventing $\mathrm{S} 1$ screw loosening. It acts as an anchor, tightly holding the lumbosacral region and resisting the lever force of the thoracolumbar area applied to the lumbosacral zone. Thus, extension of a long fusion to the pelvis with iliac screws results in a good sagittal alignment and good clinical outcome $(6,22)$. The findings of this study are consistent with previous reports: in the iliac group, SVA significantly decreased from $97 \mathrm{~mm}$ to $65 \mathrm{~mm}$ and LL increased from $27.69^{\circ}$ to $39.95^{\circ}$. Many previous studies have reported improvement in ODI score with iliac fixation $(3,16)$. In a study of 55 patients by Chang et al., ODI score significantly improved after 2 years in 25 patients who underwent iliac fixation (3). In another study of 13 patients, Hyun et al. reported that ODI score decreased from 40 to 17.5 after a follow-up of 33 months (14). In addition, Kelly et al.found a significantly greater improvement in ODI score in pelvic fixation patients than control patients at 1 year (16).

Status of the lumbosacral region may be one of the reasons for the difference in ODI score change between the groups in this study. It is still a matter of debate whether to leave the lumbosacral joint mobile in long-segment fusion patients 

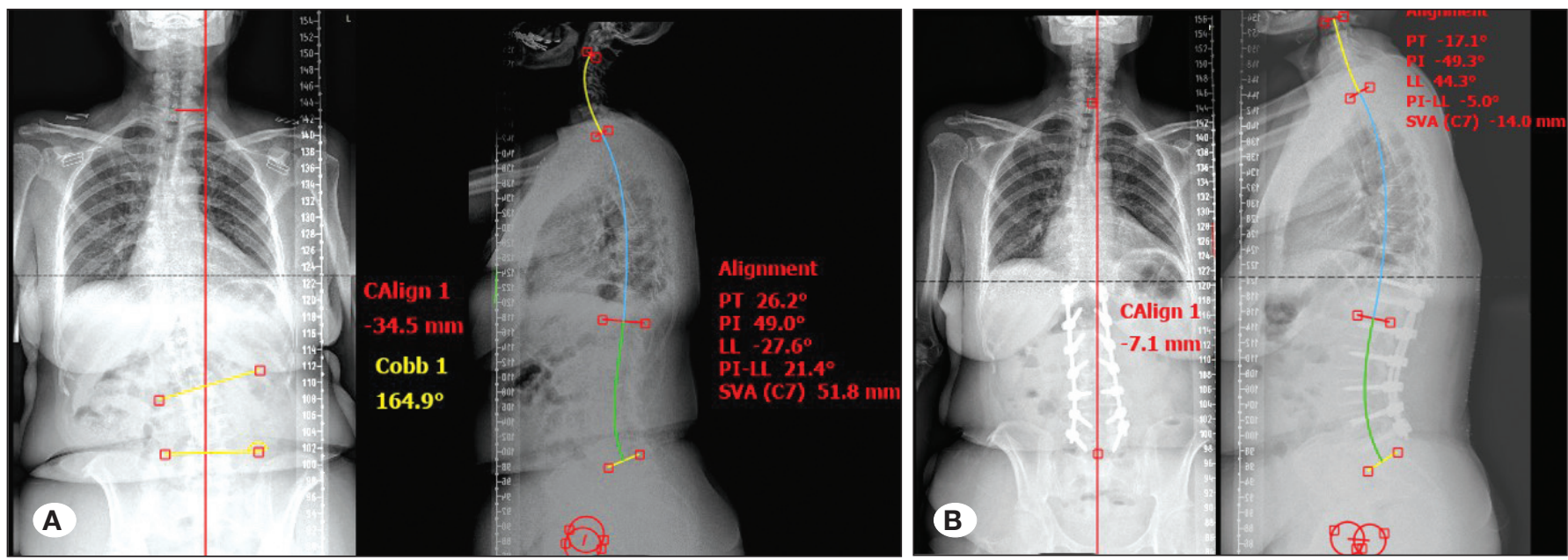

Figure 1: Standing preoperative (A) and 2-year postoperative (B) anteroposterior and lateral radiographs of a 64-year-old woman who underwent a posterior instrumented fusion from T11-L5. LL improved from $27^{\circ}$ to $44^{\circ}$.
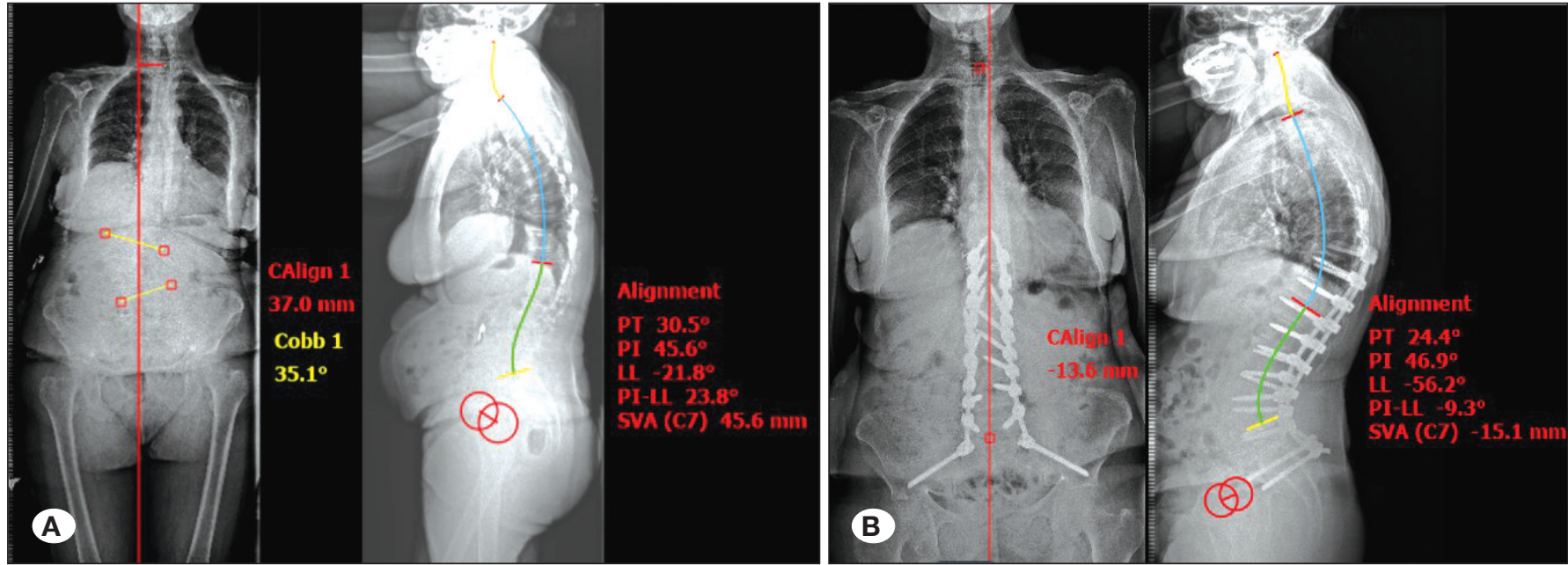

Figure 2: Standing preoperative (A) and 2-year postoperative (B) anteroposterior and lateral radiographs of a 71-year-old woman who underwent a posterior instrumented fusion from T10-llium. LL improved from $21^{\circ}$ to $56^{\circ}$.

$(8,31)$. The L5-S1 disc space, as the most mobile part of the spine, is important for good quality of life in patients with high ambulatory capacity. Spine surgeons are also of ten reluctant to incorporate the sacrum into a fusion because of its horizontal slope and low spongious bone content, which may lead to pseudoarthrosis. Indications for lumbosacral fixation have been reported in patients with thoracolumbar deformities and include L5-S1 disc degeneration, L5 spondylolysis, previous L5-S1 decompression, and lumbosacral stenosis requiring decompression $(5,8)$. Some authors have also stated that additional iliac fixation is necessary to avoid lumbosacral failure and maintain better spinal alignment (29). On the other hand, in cases where the fusion is terminated at L5, there is a risk of adjacent segment degeneration developing at L5-S1. However, findings regarding adjacent segment degeneration have differed among previous studies. In a study of 306 adult scoliosis patients by Charosky et al., adjacent segment disease was reported in $8.7 \%$ (4). In another study of 16 adult scoliosis patients with the distal end of the fusion construct at L5, Brown et al. found L5-S1 segment degeneration in 6 patients $(38 \%)$ in a 32 month follow-up period and 3 of those patients required revision surgery (2). Edwards et al. followed 31 patients for 5.6 years and found that $61 \%$ (19 patients) developed L5-S1 segment degeneration with 4 patients requiring revision surgery (8). In a 9.4-year follow-up study by Kuhns et al., $69 \%$ of the patients developed adjacent segment degeneration (20). In this study, postoperative major L5-S1 degeneration was seen in 11 of $36(31 \%)$ patients in the L5 group. Two patients with back and leg pain were diagnosed with distal adjacent segment disease and required revision surgery for symptom relief. Patients with minor degenerative changes were treated conservatively.

The main limitations of this study were its low number of patients and retrospective design. Furthermore, coronal balance was not evaluated. 


\section{CONCLUSION}

In this study, long-term results were evaluated based on distal fusion end point. Although each group showed good clinical results, the iliac group had better health-related quality of life. Iliac fixation can therefore be recommended to correct sagittal plane deformities. The L5 group also had good clinical outcomes, which can be attributed to relative improvement in SVA and PT. There are optimal sagittal balance parameter values for every age group, even for each patient. In the elderly population, higher SVA can be tolerated. Satisfactory fusion and adequate decompression of neural structures can be achieved for patients using appropriate age-matched parameters.

\section{REFERENCES}

1. Banno T, Hasegawa T, Yamato Y, Kobayashi S, Togawa D, Oe $S$, Mihara Y, Matsuyama Y: The prevalence and risk factors of iliac screw loosening after adult spinal deformity surgery. Spine (Phila Pa 1976) 42(17):E1024-E1030, 2017

2. Brown KM, Ludwig SC, Gelb DE: Radiographic predictors of outcome after long fusion to L5 in adult scoliosis. J Spinal Disord Tech 17(5):358-366, 2004

3. Chang DG, Ha KY, Kim YH, Lee EW: Spinopelvic alignment by different surgical methods in the treatment of degenerative sagittal imbalance of the lumbar spine. Clinical Spine Surgery 30(4):E390-E397, 2017

4. Charosky S, Guigui P, Blamoutier A, Roussouly P, Chopin D: Complications and risk factors of primary adult scoliosis surgery. Spine (Phila Pa 1976) 37(8):693-700, 2012

5. Cho KJ, Suk SI, Park SR, Kim JH, Choi SW, Yoon YH, Won MH: Arthrodesis to $L 5$ versus $S 1$ in long instrumentation and fusion for degenerative lumbar scoliosis. Eur Spine J 18(4):531-537, 2009

6. Cho KJ, Suk SI, Park SR, Kim, JH, Kang SB, Kim HS, Oh SJ: Risk factors of sagittal decompensation after long posterior instrumentation and fusion for degenerative lumbar scoliosis. Spine (Phila Pa 1976) 35(17):1595-1601, 2010

7. Diebo BG, Varghese JJ, Lafage R, Schwab FJ, Lafage V: Sagittal alignment of the spine: What do you need to know? Clin Neurol Neurosurg 139:295-301, 2015

8. Edwards CC, Bridwell KH, Patel A, Rinella AS, Jung Kim Y, Berra A, Della Rocca G, Lenke L: Thoracolumbar deformity arthrodesis to L5 in adults: The fate of the L5-S1 disc. Spine (Phila Pa 1976) 28(18):2122-2131, 2003

9. Faraj SSA, De Kleuver M, Vila-Casademunt A, Holewijn R, Obeid I, Acaroğlu E, Alanay A, Kleinstück F, Pérez-Grueso F, Pellisé F: Sagittal radiographic parameters demonstrate weak correlations with pretreatment patient-reported health-related quality of life measures in symptomatic de novo degenerative lumbar scoliosis: A European multicenter analysis. J Neurosurg Spine 28(6):573-580, 2018

10. Glassman SD, Berven S, Bridwell K, Horton W, Dimar JR: Correlation of radiographic parameters and clinical symptoms in adult scoliosis. Spine (Phila Pa 1976) 30(6):682-688, 2005
11. Glassman SD, Bridwell KM, Dimar JR, Horton W, Berven S, Schwab F: The impact of positive sagittal balance in adult spinal deformity. Spine (Phila Pa 1976) 30(18):2024-2029, 2005

12. Guler UO, Cetin E, Yaman O, Pellise F, Casademut AV, Sabat MD, Alanay A, Grueso FSP, Acaroglu E: Sacropelvic fixation in adult spinal deformity (ASD); a very high rate of mechanical failure. Eur Spine J 24(5):1085-1091, 2015

13. Hasegawa K, Okamoto M, Hatsushikano S, Shimoda H, Ono M, Watanabe K: Normative values of spino-pelvic sagittal alignment, balance, age, and health-related quality of life in a cohort of healthy adult subjects. Eur Spine J 25(11):36753686, 2016

14. Hyun SJ, Rhim SC, Kim YJ, Kim YB: A mid-term follow-up result of spinopelvic fixation using iliac screws for lumbosacral fusion. J Korean Neurosurg Soc 48(4):347-353, 2010

15. Iyer S, Lenke LG, Nemani VM, Albert T, Sides B, Metz LN, Cunningham ME, Kim HJ: Variations in sagittal alignment parameters based on age. Spine (Phila Pa 1976) 41(23):18261836, 2016

16. Kelly PD, Sivaganesan A, Chotai S, Parker SL, McGirt MJ, Devin CJ: Matched-pair cohort study of 1-year patientreported outcomes following pelvic fixation. Spine J 16(6):742747,2016

17. Kim JS, Kim SM: Surgical outcomes of post-fusion lumbar flatback deformity with sagittal imbalance. J Korean Neurosurg Soc 59(6):615-621, 2016

18. Kim YJ, Bridwell KH, Lenke LG, Rhim S, Cheh G: Pseudarthrosis in long adult spinal deformity instrumentation and fusion to the sacrum: Prevalence and risk factor analysis of 144 cases. Spine (Phila Pa 1976) 31(20):2329-2336, 2006

19. Koller H, Pfanz C, Meier O, Hitzl W, Mayer M, Bullmann V, Schulte T: Factors influencing radiographic and clinical outcomes in adult scoliosis surgery: A study of 448 European patients. Eur Spine J 25(2):532-548, 2016

20. Kuhns C a, Bridwell KH, Lenke LG, Amor C, Lehman R, Buchowski J, Edwards C, Christine B: Thoracolumbar deformity arthrodesis stopping at L5: Fate of the L5-S1 disc, minimum 5-year follow-up. Spine (Phila Pa 1976) 32(24):27712776, 2007

21. Lafage R, Schwab F, Challier V, Henry J, Gum J, Smith J, Hostin R, Shaffrey C, Kim H, Ames C, Scheer J: Defining spino-pelvic alignment thresholds. Spine (Phila Pa 1976) 41(1):62-68, 2016

22. O’Neill KR, Bridwell KH, Lenke LG, Chuntarapas T, Dorward I, Neuman B, Ahmad A, Baldus C: Extension of spine fusion to the sacrum following long fusions for deformity correction. Spine (Phila Pa 1976) 39(12):953-962, 2014

23. Pfirrmann CWA, Metzdorf A, Zanetti M, Hodler J, Boos N: Magnetic resonance classification of lumbar intervertebral disc degeneration. Spine (Phila Pa 1976) 26(17):1873-1878, 2001

24. Ploumis A, Liu H, Mehbod AA, Transfeldt EE, Winter RB: A correlation of radiographic and functional measurements in adult degenerative scoliosis. Spine (Phila Pa 1976) 34(15):15811584, 2009 
25. Polly DW, Hamill CL, Bridwell KH: Debate: To fuse or not to fuse to the sacrum, the fate of the L5-S1 disc. Spine (Phila Pa 1976) 31 Suppl 19:S179-184, 2006

26. Schwab F, Patel A, Ungar B, Farcy JP, Lafage V: Adult spinal deformity-postoperative standing imbalance. Spine (Phila Pa 1976) 35(25):2224-2231, 2010

27. Simon J, Longis PM, Passuti N: Correlation between radiographic parameters and functional scores in degenerative lumbar and thoracolumbar scoliosis. Orthop Traumatol Surg Res 103(2):285-290, 2017

28. Smith JS, Klineberg E, Schwab F, Shaffrey C, Moal B, Ames C, Hostin R, Fu KG, Burton D, Akbarnia B, Gupta M, Hart R, Bess S, Lafage V: Change in classification grade by the SRSschwab adult spinal deformity classification predicts impact on health-related quality of life measures. Spine (Phila $\mathrm{Pa}$ 1976) 38(19):1663-1671, 2013
29. Yasuda T, Hasegawa T, Yamato Y, Kobayashi S, Togawa D, Banno T, Arima H, Oe S, Matsuyama Y: Lumbosacral junctional failures after long spinal fusion for adult spinal deformity? Which vertebra is the preferred distal instrumented vertebra? Spine Deform 4(5):378-384, 2016

30. Yokoyama K, Kawanishi M, Yamada M, Tanaka H, Ito $Y$, Kawabata S, Kuroiwa T: Age-related variations in global spinal alignment and sagittal balance in asymptomatic Japanese adults. Neurol Res 39(5):414-418, 2017

31. Zaborovskii N, Ptashnikov D, Mikhaylov D, Smekalenkov O, Masevnin S, Lapaeva O, Mooraby Z: Spinal deformity in elderly patients: Comparison of two distal termination sites of lumbar curve fusion. Eur J Orthop Surg Traumatol 27(1):73-78, 2017 